\title{
Multiple laser shock peening effects on residual stress distribution and fatigue crack growth behaviour of 316L stainless steel
}

\author{
Rasool Bikdeloo $^{a}$, Gholam Hossein Farrahi ${ }^{a^{*}}$, Ali Mehmanparast ${ }^{\text {b }}$, Seyed Mohammad \\ Mahdavi ${ }^{\mathrm{c}}$ \\ ${ }^{a}$ School of Mechanical Engineering, Sharif University of Technology, Tehran, Iran \\ ${ }^{b}$ Offshore Renewable Energy Engineering Centre, Cranfield University, Bedfordshire, UK \\ ${ }^{c}$ Department of Physics, Sharif University of Technology, Tehran, Iran \\ "Corresponding author, email address: farrahi@sharif.edu, Phone: +982166165533, Fax:+982166000021
}

\begin{abstract}
Laser shock peening (LSP) is one of the life enhancement processes by inducing compressive residual stresses into the material. The effects of repeating LSP pattern on the residual stress is numerically investigated in this study. FEM results have shown that increasing the number of peening impacts increases the magnitude and depth of compressive residual stress. Moreover, the effects of repeating LSP pattern on fatigue crack growth properties were experimentally investigated by performing tests on C(T) specimens made of 316L stainless steel. The test results have shown that the fatigue crack growth life is very sensitive to the number of peening impacts and the fatigue crack growth rates decrease by repeating LSP patterns on the test specimens.
\end{abstract}

Keywords: Laser shock peening, residual stress, multiple peening, fatigue life, fatigue crack growth rate

\section{1- Introduction}

Fatigue is known as one of the major failure mechanisms in the lifespan of engineering components and structures. The main cause of fatigue damage in metallic materials is the creation and growth of cracks which eventually reach a critical point and ultimately fracture occurs [1]. Studies have shown that beneficial compressive residual stresses can play a significant role in the reduction of fatigue crack growth rate and reduction of fatigue fracture failures [1-4].

In order to reduce and prevent fatigue failure, various processes have been proposed in the literature, known as life improvement processes, such as shot peening [5], water jet peening [6], ultrasonic peening [7], etc. Laser Shock Peening (LSP) is one of the life improvement processes which is based on the radiation of a laser beam at a very short time (several nanoseconds) on the material surface [8]. The schematic of this process is shown in figure 1. The radiated laser passes through the transparent overlay, encounters the absorbing coating and evaporates it. Consequently, the surface of the material 
is ionized and the plasma is created [9]. The absorbent coating is used to protect the surface of the metal [10] and a transparent overlay, like water, is used for increasing plasma pressure [11].

Expansion of plasma is prevented because it is trapped between the metal surface and the transparent overlay. This process causes a considerable increase in the pressure up to several GPa in nanoseconds. As a result, shock waves are generated and penetrated into the material [12]. The shock waves cause the material to plastically deform. As the subsurface stresses exceed the Hugoniot Elastic Limit (the compressive yield strength of material under a shock condition), compressive residual stress remains in the material [13].

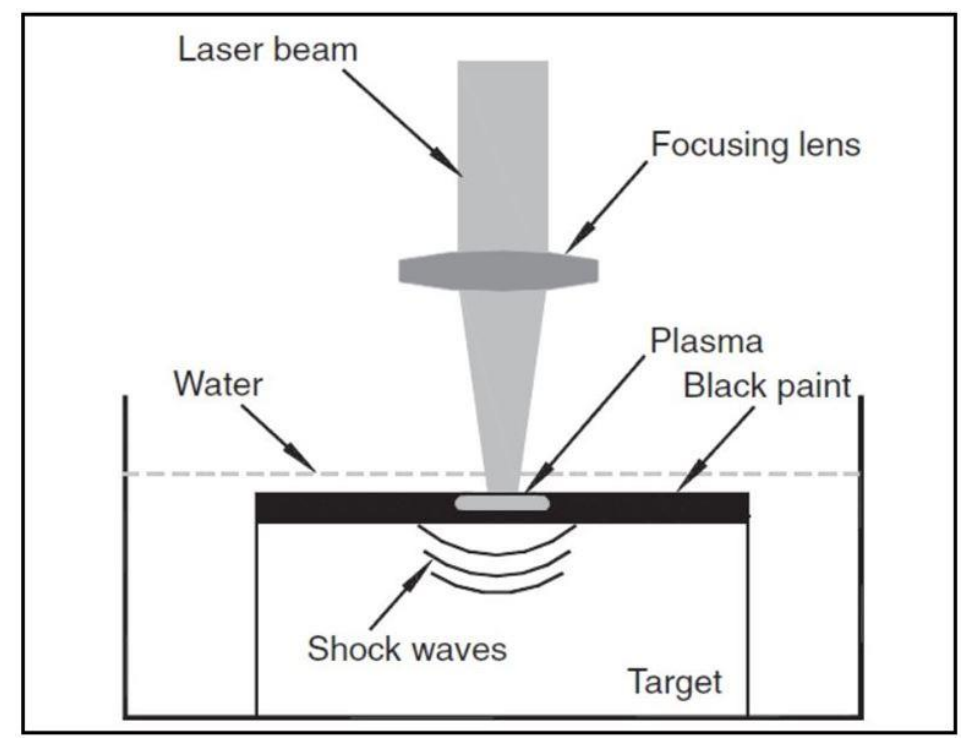

Fig. 1. Schematic of laser shock peening process [9]

Various studies have been performed in the past to investigate the effects of process parameters including laser spot size [14], laser energy [15], pressure duration [16], specimen geometry [17] as well as overlapping rate $[18,19]$ on the residual stress distribution and fatigue crack growth behaviour in a wide range of metallic materials. Several studies in the literature were focused on the investigation of multiple peening effects on the induced residual stress profile through Finite Element Method (FEM) simulations and laboratory experiments. Ding and Ye [20], Peyre et al. [21] and Kim et al. [16] developed axisymmetric 2D FEM models for simulation of multiple impacts at single shot location. Other studies [16, 22, 23] used quarter 3D FEM models with symmetric boundary surfaces for simulation of LSP and studied the effects of process parameters such as laser spot size and peak pressure on the residual stress. Hu et al. [24] developed a 3D model for simulation of single and multiple shots in one location.

Other studies have investigated the effects of multiple peening on the mechanical properties and fatigue life of materials. Lu et al. [25] studied the effects of multiple impacts on the grain refinement mechanism of 304 stainless steel. Zhang et al. [26] found that fatigue strength of Ti-6Al-4V samples 
increased by changing the increment number of laser spots. Zhou et al. [27] reported that fatigue crack initiation location transferred from the top surface to the sub-surface and the distance of fatigue crack initiation location from the top surface increased by increasing the impacts number. Liucheng et al. [28] observed that micro hardness of titanium alloy increased by multiple impacts. Shen et al. [29] reported that multiple peening could effectively improve the sliding wear property of $\mathrm{Ti}-6 \mathrm{Al}-7 \mathrm{Nb}$ alloy. Umapathi and swaroop [30] showed that the surface roughness was significantly affected by multiple peening. Wang et al. [31] found that the wear mass loss and electrochemical corrosion rate of shipbuilding 5083Al alloy samples reduced by increasing impacts number. Yang et al. [32] studied the effects of multiple peening on the microstructure and properties of 2195 Al-Li alloy. They reported that the grain size became finer and the density of defects became higher after 3 times LSP compared to a single LSP. Li et al. [33] reported that vibration fatigue life of TC6 titanium alloy increased by multiple impacts. Chen et al. [34] investigated the effects of multiple peening on the mechanical properties of $40 \mathrm{CrNiMo}$ steel and observed that the yield strength, tensile strength, elongation and surface roughness increased by increasing impacts number.

The review of the existing studies in the literature shows that most of the numerical studies have investigated the effects of multiple impacts in one spot location while in real applications several spots at different locations will be impacted. Also less attention has been paid to the effects of multiple impacts on the fatigue crack growth properties. In this study, a 3D finite element model is developed in order to predict the residual stress field in the material with special attention to the effects of repeating LSP pattern on the surface and in-depth residual stresses. Moreover, the effects of repeating LSP pattern on the fatigue crack growth properties are investigated experimentally and the fatigue crack growth life, fatigue crack growth rate and fracture surfaces are examined and discussed.

\section{2- Finite Element Model Set-up for LSP Simulation}

Numerical simulation of LSP contains several steps which include defining material properties, type of analysis, loading condition and mesh sensitivity analysis. In this study, a 3D FEM model is developed using ABAQUS to analyse LSP induced residual stress profiles in a predefined region with dimensions of $30 \times 30 \times 6 \mathrm{~mm}^{3}$ (length $\times$ width $\times$ thickness) as schematically shown in Figure 2 . In order to set-up the FEM mode, a benchmark simulation was initially performed and validated following the work of Ding and Ye [20]. Secondly, the effect of repeating LSP pattern on the residual stresses is considered and included in the model. For this purpose, 2 rows with 5 pulses in each row are simulated. The overlap rate between adjacent pulses is kept $0 \%$ along both the $\mathrm{X}$ and $\mathrm{Y}$ directions. As shown in Figure 2, the first pulse starts from point A, the swept direction is along $\mathrm{X}$ axis and the final spot is impacted at point B. For multiple LSP impacts, this pattern is repeated once, twice and three times the examined samples are referred to as LSPed specimens with 2, 3 and 4 peening impacts, 
respectively. Finally, the effects of multiple LSP impacts on the in-depth and surface residual stresses are investigated.

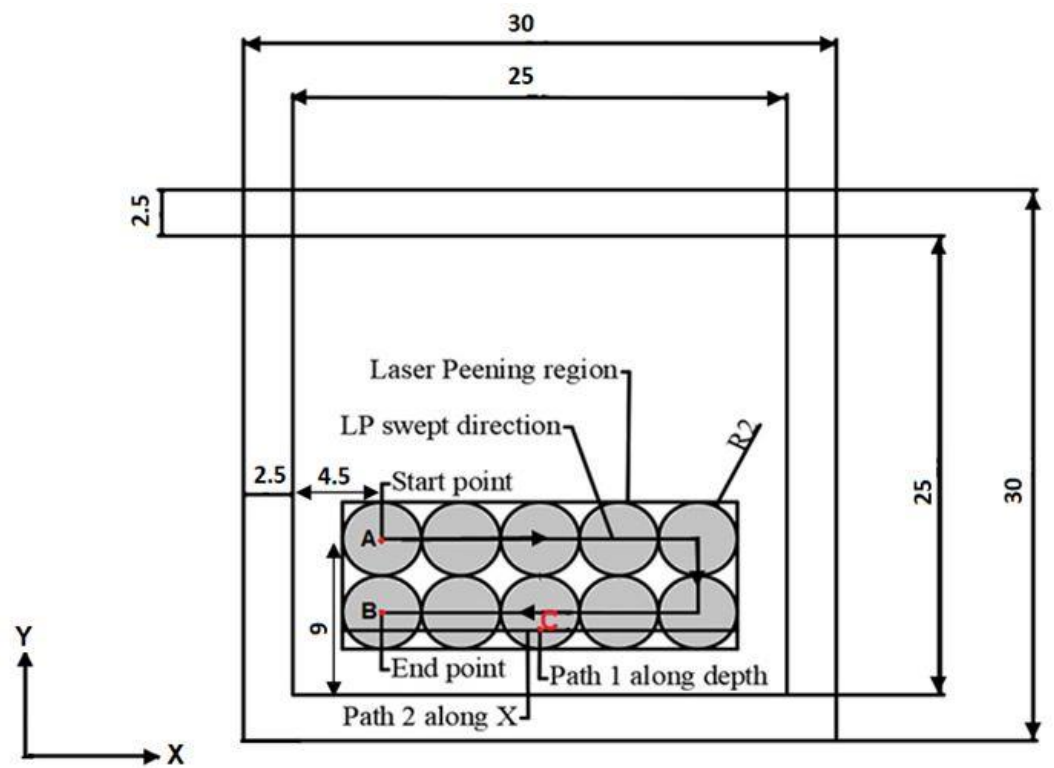

Fig. 2. Schematic of laser peening procedure in numerical simulation )All lengths are specified in $\mathrm{mm}($

\section{1- Material properties}

LSP is a very fast process with a very high strain rate of around $10^{-6} \mathrm{~S}^{-1}$. The behaviour of material at this high strain rate is different from low strain rates. Therefore, an appropriate material model which accounts for this high strain rate must be employed in the analysis. In processes which include impact and shock wave propagation, the Johnson-Cook material model is recommended to be used for high strain rates which can be defined as [35]:

$$
\sigma=\left[A+B \varepsilon^{n}\right]\left[1+C \ln \frac{\dot{\varepsilon}}{\dot{\varepsilon}_{0}}\right]\left[1-\left(\frac{T-T_{r}}{T_{m}-T_{r}}\right)^{m}\right]
$$

where $T$ is the temperature of material during the process, $T_{r}$ is the room temperature, $T_{m}$ is the melting point of material, ???. In this equation, the first term describes strain hardening and expresses combined elastic-plastic behaviour of the material. The second term considers the strain rate and the third term indicates thermal effects. In this equation, the thermal effects induced by the shock pressure is negligible, therefore the last term in the Johnson-cook model can be neglected [19, 36, 37]. The material used in this study is $316 \mathrm{~L}$ stainless steel. The Johnson-Cook parameters for this material are summarized in Table 1.

\section{Table 1}

Johnson-Cook parameters for 316L stainless steel [36]

\begin{tabular}{ccccc}
\hline $\mathrm{A}(\mathrm{Mpa})$ & $\mathrm{B}(\mathrm{Mpa})$ & $\mathrm{C}$ & $\mathrm{n}$ & $\dot{\varepsilon}_{0}$ \\
\hline 300 & 600 & 0.045 & 0.35 & 1 \\
\hline
\end{tabular}




\section{2- Design of simulation step times}

There are two distinct stages in the LSP simulation process. In the first stage, a very high pressure is applied to the material in a short time and the material is subjected to plasticity. ABAQUS/Explicit is a nonlinear time integration finite element code which is designed for high speed and short time dynamic events and is employed in this study to implement the first step of the LSP simulation [22, $38,39]$. In the second step, stress equilibrium needs to be achieved in the material during much longer simulation times. ABAQUS/Standard is used for this step as recommended in similar studies found in the literature $[18,22,38]$. The combination of ABAQUS explicit and standard steps in LSP models reduces the simulation time, however for simulating multiple impacts a restart file from ABAQUS/Standard needs to be imported into ABAQUS/Explicit at the end of each pass. This procedure must be repeated depending on the number of impacts and known to be time consuming $[20,38]$. In order to optimize the simulation time in this work, ABAQUS/Explicit is used for the analysis of both steps. The first step time is considered to be $200 \mathrm{~ns}$ according to account for the short duration of shock wave propagation. The second step time is set to $20000 \mathrm{~ns}$ in order to achieve the equilibrium of stresses into the material and reach the residual stress field.

\section{3- Loading conditions}

The aim of this study is not to simulate the creating and expansion of different plasma phases. Ins tead, the main goal of this work is to obtain the residual stress fields in the material under different number of impacts. Most of the literature studies have used triangular ramp for estimation of plasma pressure in which pressure rises rapidly to the peak value and then decreases slowly to point zero [20, $24,38]$. For this purpose the peak plasma pressure can be estimated using the following equations [40]:

$$
\begin{aligned}
& P(G P a)=0.01 \sqrt{\frac{\alpha}{2 \alpha+3}} \sqrt{Z\left(g / m^{2} s^{1}\right)} \sqrt{I_{0}\left(G W / \mathrm{cm}^{2}\right)} \\
& \frac{2}{Z}=\frac{1}{Z_{1}}+\frac{1}{Z_{2}}
\end{aligned}
$$

In equation $2, \alpha$ is the efficiency of interaction and is taken as 0.25 in this work [41]. $I_{0}$ is laser power intensity which is approximately $2.6 \frac{\mathrm{GW}}{\mathrm{cm}^{2}}$ based on laser parameters. In the equation $3, \mathrm{Z}_{1}$ is acoustic impedance of the target material which is taken as $3.7 \times 10^{6}\left(\mathrm{gr} / \mathrm{cm}^{2} \mathrm{~s}^{1}\right)$ for $316 \mathrm{~L}$ stainless steel [36] and $Z_{2}$ is acoustic impedance of confining water and is taken as $0.165 \times 10^{6}\left(\mathrm{gr}^{\mathrm{gr}} \mathrm{cm}^{2} \mathrm{~s}^{1}\right)$ [41] . Using these parameters the peak pressure is found to be approximately $2.5 \mathrm{GPa}$. The plasma pressure 
time is around 4-6 times greater than laser time [42] and for the 5ns full width at half maximum (FWHM) laser pulse used in this work, the pressure pulse duration has been assumed to be 40ns.

As the spatial distribution of pressure pulse is extremely difficult to investigate experimentally, most studies assume uniform distribution at the laser impact region [20, 24, 38, 42]. In this work, the uniform distribution is assumed for spatial distribution of pressure pulse. Moreover, VDLOAD subroutine is used to apply temporal and spatial distribution of pressure pulse as well as scanning pattern.

\section{4- Finite element model}

The FEM model is divided into two regions. The first region is located with $2.5 \mathrm{~mm}$ distance from edges and $2 \mathrm{~mm}$ distance from the bottom, and elastic-plastic properties have been assigned to it. C3D8R elements have been assigned to this region and the optimum number of elements found from the mesh sensitivity analysis in this regions is 2,500,000. A non-uniform scheme is used along indepth direction and the element size is coarsened away from the surface. The minimum element size in this region is $100 \mu \mathrm{m} \times 100 \mu \mathrm{m} \times 16 \mu \mathrm{m}$. For the rest of the model infinite elements are used as nonreflecting boundaries for shock wave attenuation. Overall, 102,500 CIN3D8 elements with only elastic properties are used around and under the finite region which is shown in Figure 3.

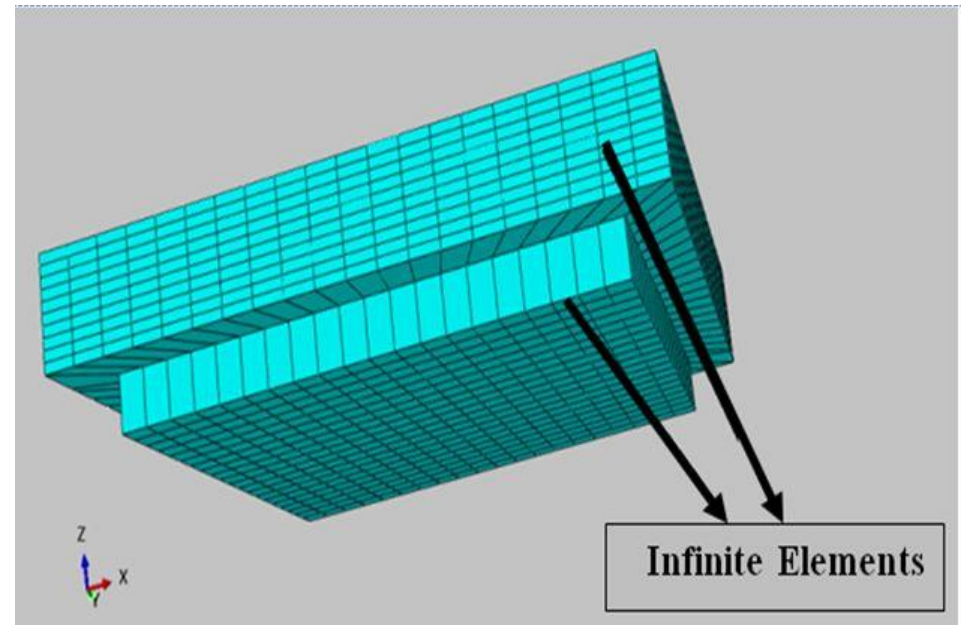

Fig. 3. 3D Finite Element model for LSP simulation

\section{3- Residual Stress Prediction Results from LSP Simulations}

\section{1- Benchmark simulation and verification}

The experimental and numerical results from the work conducted by Ding and Ye [20] are used to examine the reliability of the numerical simulations performed in this work. Ding and Ye [20] developed a 2D model for simulation of laser peening of 35CD4 steel alloy. Laser beam diameter, 
peak pressure and laser FWHM used in their work were $8 \mathrm{~mm}, 2.8 \mathrm{GPa}$ and 50ns, respectively. They assumed triangular ramp for plasma pressure estimation in which pressure rises linearly to the peak value in a duration of 50ns and decays linearly during the following 50ns. The in-depth and surface residual stress prediction results from the current study are presented in Figure 4 and compared with experimental and numerical results from [20]. In-depth residual and surface residual stress values are measured at $3.5 \mathrm{~mm}$ distance from the centre and along the line passing through the laser centre in $\mathrm{X}$ direction, respectively. As seen in Figure 4 (a) and figure 4 (b), the numerical results from the 3D model developed in this study are in good agreement with experimental and numerical results obtained by Ding and Ye [20] and shows similar quantitative and qualitative trends.

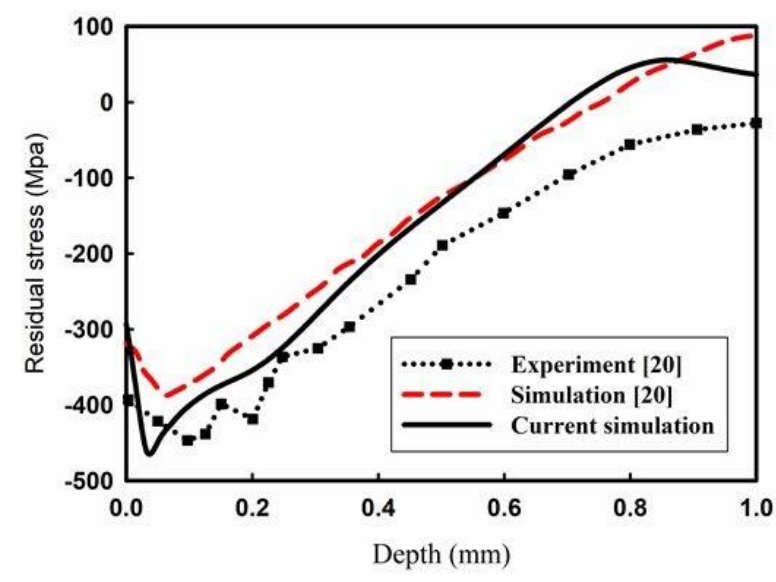

a)

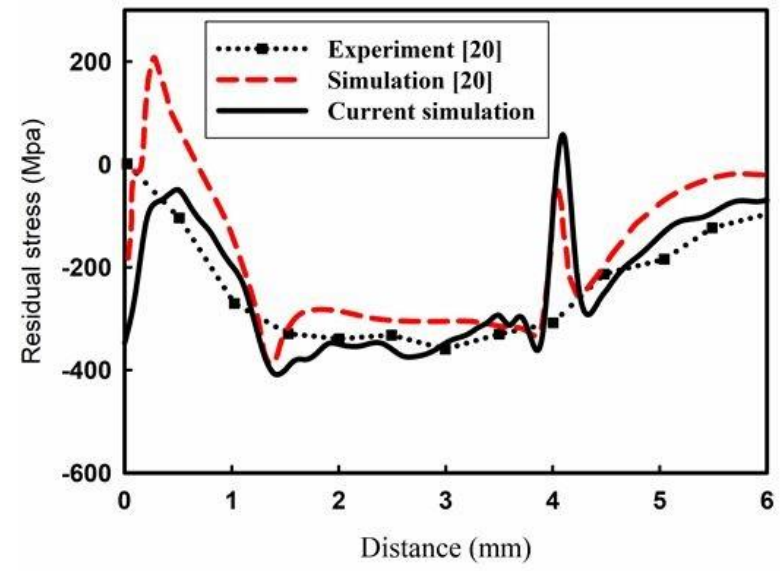

b)

Fig. 4. Residual stress distribution in benchmark simulation (a) in-depth results (b) surface results

\section{2- The influence of different loading scenarios on residual stress predictions}

According to the pressure pulses used in different studies [18, 20, 42, 43], three different load histories are considered which are shown in Figure 5. In the first loading condition (i.e. load 1), the pressure rises linearly to the peak value in a duration of 20ns and then decays linearly during the following 20ns which is similar to the estimations performed in [16, 20, 24]. In the second one (i.e. load 2), the pressure increases linearly to the peak value in the first $5 \mathrm{~ns}$ and then decreases to zero in the following 40ns. This loading condition is referred to as sharp rise loading and was previously used in other studies $[38,43,44]$. Finally, in the last loading case (i.e. load 3 ) the pressure increases rapidly to the peak value in a duration of $5 \mathrm{~ns}$ and then stays constant in the following $5 \mathrm{~ns}$ and finally decreases to zero until 40ns, which is similar to the works performed in $[45,46]$. 


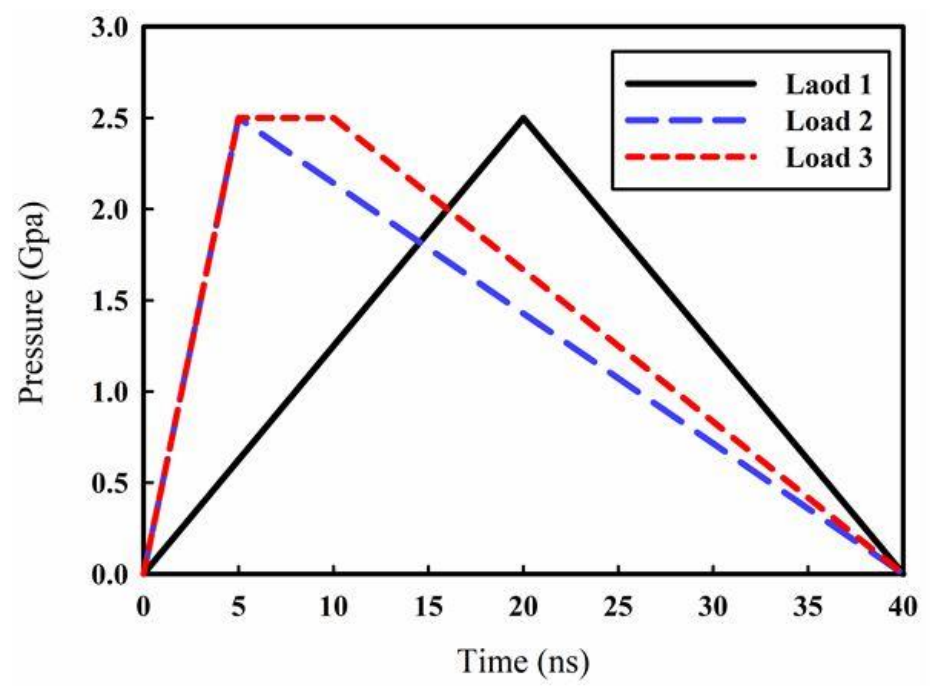

Fig. 5. Temporal loading profile of pressure pulse

In each of these three simulations, the pulse diameter is $4 \mathrm{~mm}$ and the laser impact is applied at the centre of the model. The in-depth residual stress is extracted from $1 \mathrm{~mm}$ distance from the centre. Surface residual stress is measured along the path through $\mathrm{X}$ direction which has $1 \mathrm{~mm}$ distance from the centre. The results from in-depth residual stress for different loading scenarios is shown in Figure 6(a). As seen in this figure, there is no significant difference between the predicted results for different load cases. The simulation results show that the peak compressive residual stresses are -340, -348, $337 \mathrm{MPa}$, the average residual stresses along this path are -165, -166, -182 MPa and the compressive depths are 5.89, 5.97 and $6.38 \mathrm{~mm}$ after applying load 1, load 2 and load 3 conditions, respectively. Moreover, the surface residual stress results obtained from different loading scenarios are shown in Figure 6(b). The simulation results show that the peak surface compressive residual stresses are $361,-379,-370 \mathrm{MPa}$, and the average residual stresses along this path are $-312,-323$ and $-315 \mathrm{MPa}$ for load 1, load 2 and load 3 conditions, respectively. The results show that all three loading scenarios create similar in-depth and surface residual stresses, but for preventing the effects of breakdown phenomenon, sharp-rise loading is preferred due to the fact that in this profile the peak pressure is built before the breakdown [43]. Moreover, this loading scheme is closer to the other pressure-time histories showed in other works $[11,18,47]$ for 5 6 ns FWHM laser pulses. 


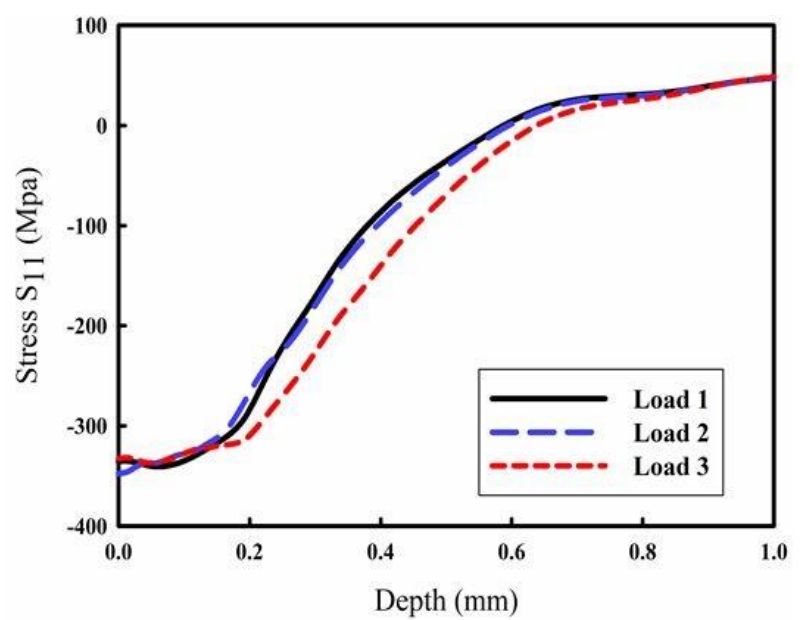

a)

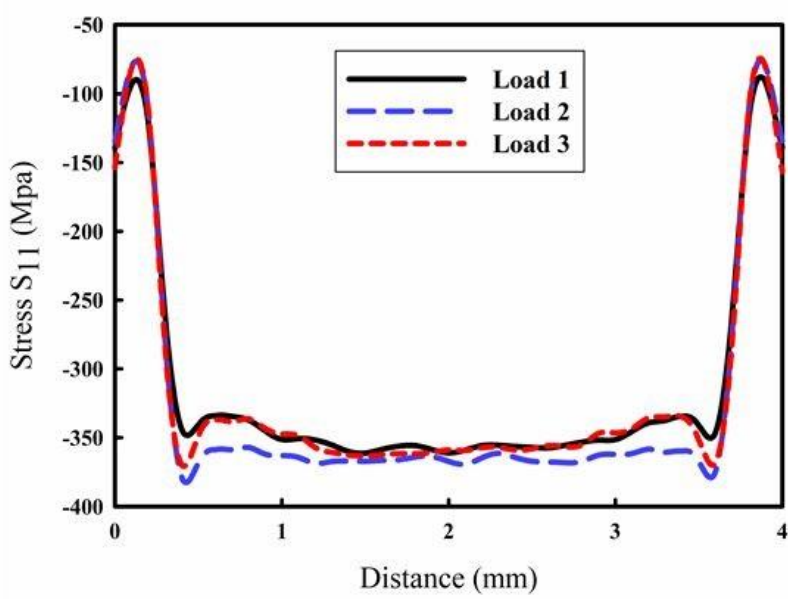

b)

Fig. 6. Comparison of residual stress distribution for different loadings (a) in-depth (b) surface

\section{3- Multiple laser impact effects on residual stress profiles}

The LSP scheme developed in this study has been used to simulate residual stresses in 2 rows, with 5 pulses in each row, for one, two, three and four impacts of peening on the outer surface. The contour map of $S_{11}$ stress distribution results for different number of peening impacts is shown in Figure 7. As seen in this figure, the maximum compressive residual stress values obtained from simulations after the $1^{\text {st }}$ impact is $428 \mathrm{MPa}$ which subsequently increases to 459,490 and $503 \mathrm{MPa}$, indicating around $7.2 \%, 6.7 \%$ and $2.6 \%$ improvement in beneficial residual stresses, after 2,3 and 4 peening impacts, respectively.

In order to compare the in-depth residual stresses, the data are extracted from a path along in-depth direction which starts from point $\mathrm{C}$ (see Figure 2, path 1). The results of in-depth residual stress for different number of peening impacts are presented in Figure 8. As seen in this figure, after the $1^{\text {st }}$ impact, the maximum compressive residual stress is predicted to be $369 \mathrm{MPa}$, which subsequently increases to 420,443 and $452 \mathrm{MPa}$ after two, three and four peening impacts, respectively. When the number of peening impacts increases from 1 to 2 , the peak compressive residual stress increases $13.8 \%$. However, when the peening impact number increase from 2 to 3 , the peak compressive residual stress improves $5.5 \%$ and only $2 \%$ increment has observed by increasing impact times from 3 to 4 . This means that the greatest percentage of improvement occurs upon 2 impacts and after that the increment of increasing beneficial residual stress becomes slower. Furthermore, by increasing the peening impact number from one to two, three and four, the depth of compressive residual stress increases from 0.652 to $0.814,0.930$ and $1.005 \mathrm{~mm}$, indicating $24.8 \%, 14.2 \%$ and $8.1 \%$ improvement after each impact, respectively. 


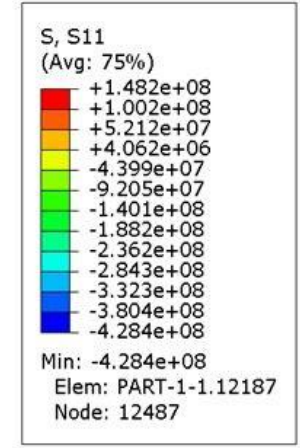

$\stackrel{Y}{Y} \rightarrow x$
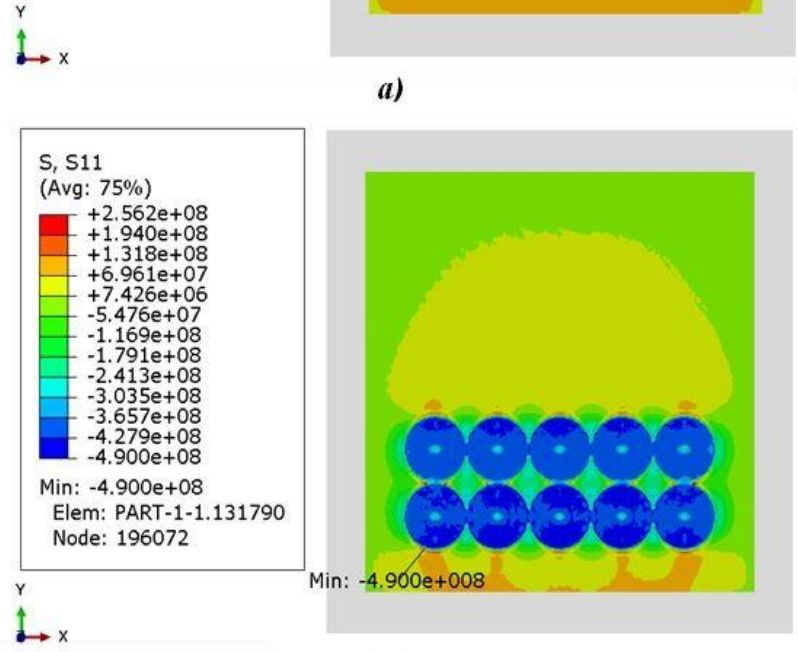

c)

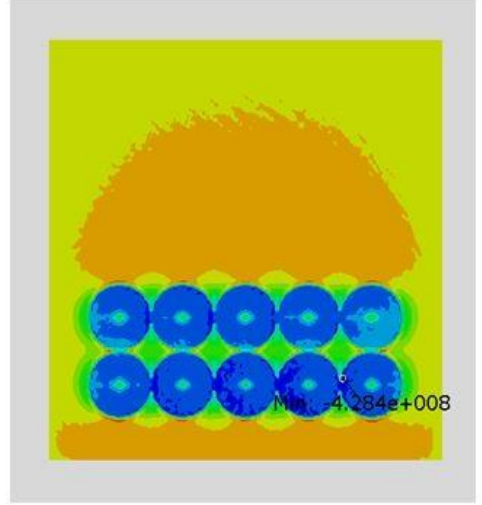

a)

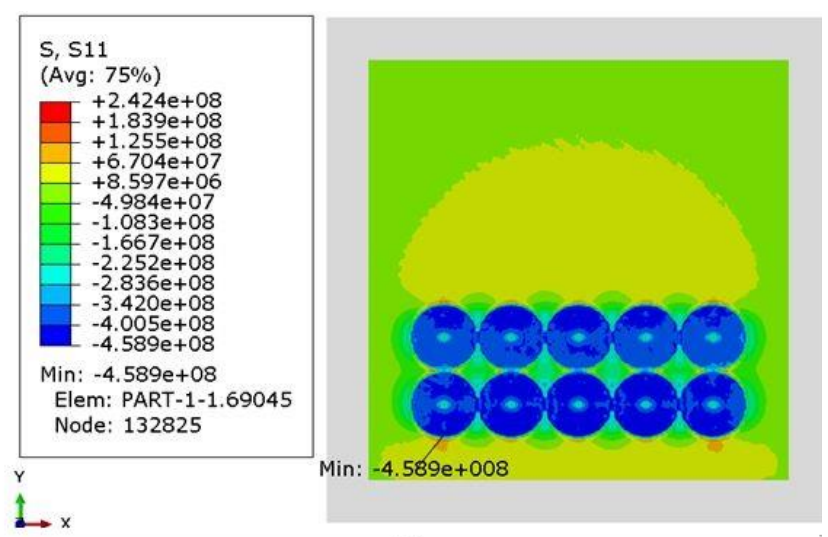

b)
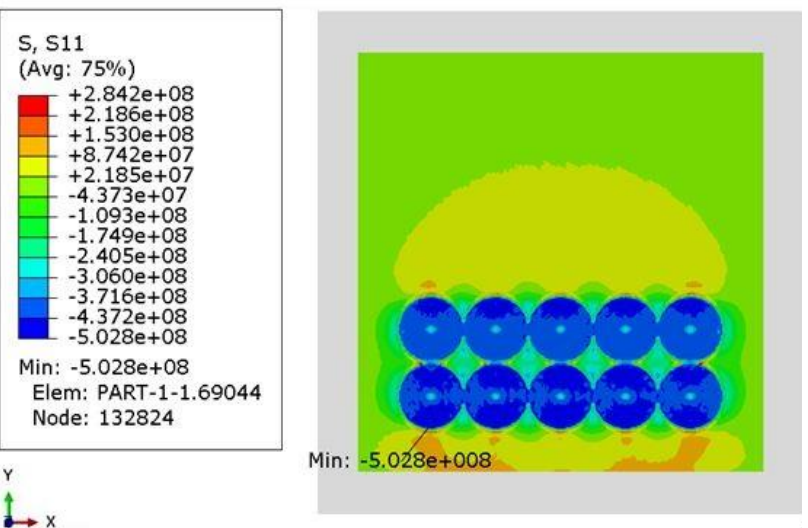

d)

Fig. 7. S11 stress distribution results after (a) 1 (b) 2 (c) 3 (d) 4 peening impacts 


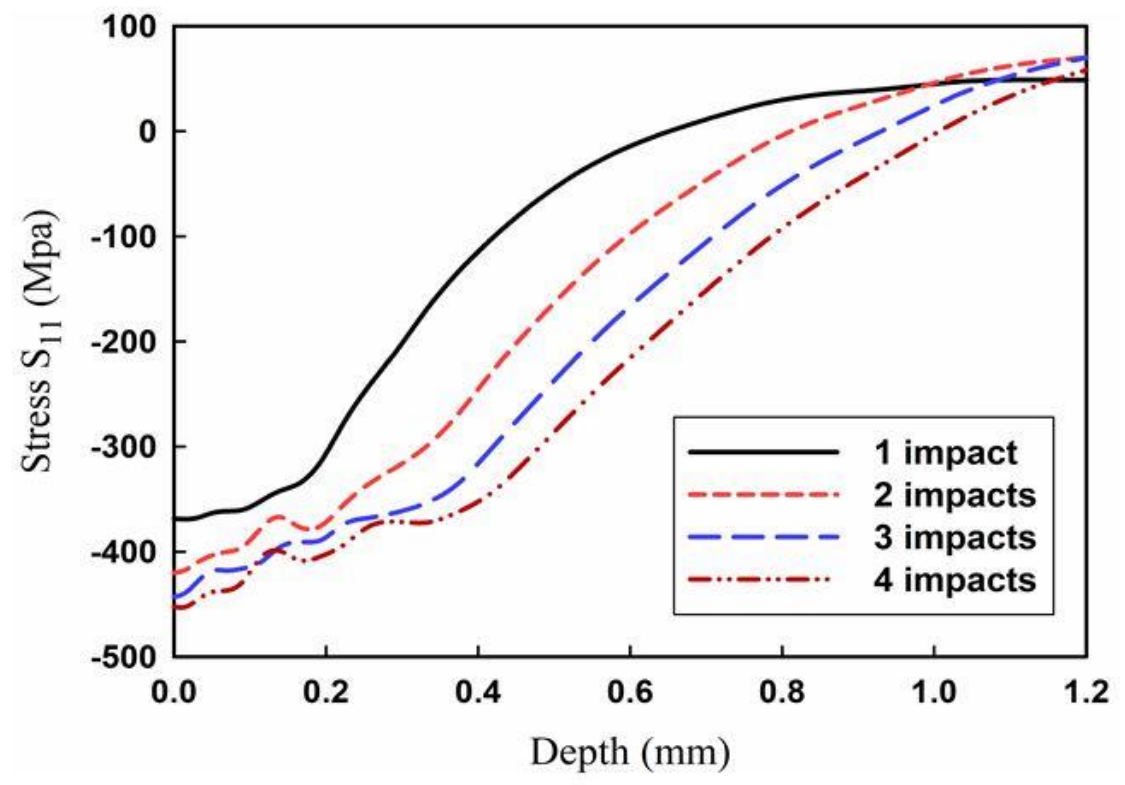

Fig. 8.Effects of multiple laser impacts on the in-depth residual stress

Figure 9 shows the surface residual stress results on a surface path along the $\mathrm{X}$ direction. The path has $6 \mathrm{~mm}$ distance from edge or $1 \mathrm{~mm}$ distance from the centre of the first row (see Figure 2, path 2). The average residual stress along this path is around $-282 \mathrm{MPa}$ after the $1^{\text {st }}$ peening impact and rises to $-316,-330$ and $-341 \mathrm{MPa}$ after 2, 3 and 4 peening impacts, respectively. The average surface residual stresses in the impact region after 1, 2, 3 and 4 impacts are -291, -326, -343 and -356 MPa, respectively. By increasing the number of peening impacts from one to two, the average surface residual stress improves by around $12 \%$. Moreover, 5.2\% improvement is observed when the number of peening impact increases from two to three and there is only a $3.8 \%$ improvement when impact times increase from three to four. The results obtained from numerical simulations show that for the in-depth compressive residual stresses, the compressive depth and average surface residual stress is improved by increasing the number of peening impacts, but the percentage improvement is decreased by increasing the number of impact times. This is due to the fact that by increasing the number of peening impacts, the saturation of residual stress occurs in the material [22, 24]. 


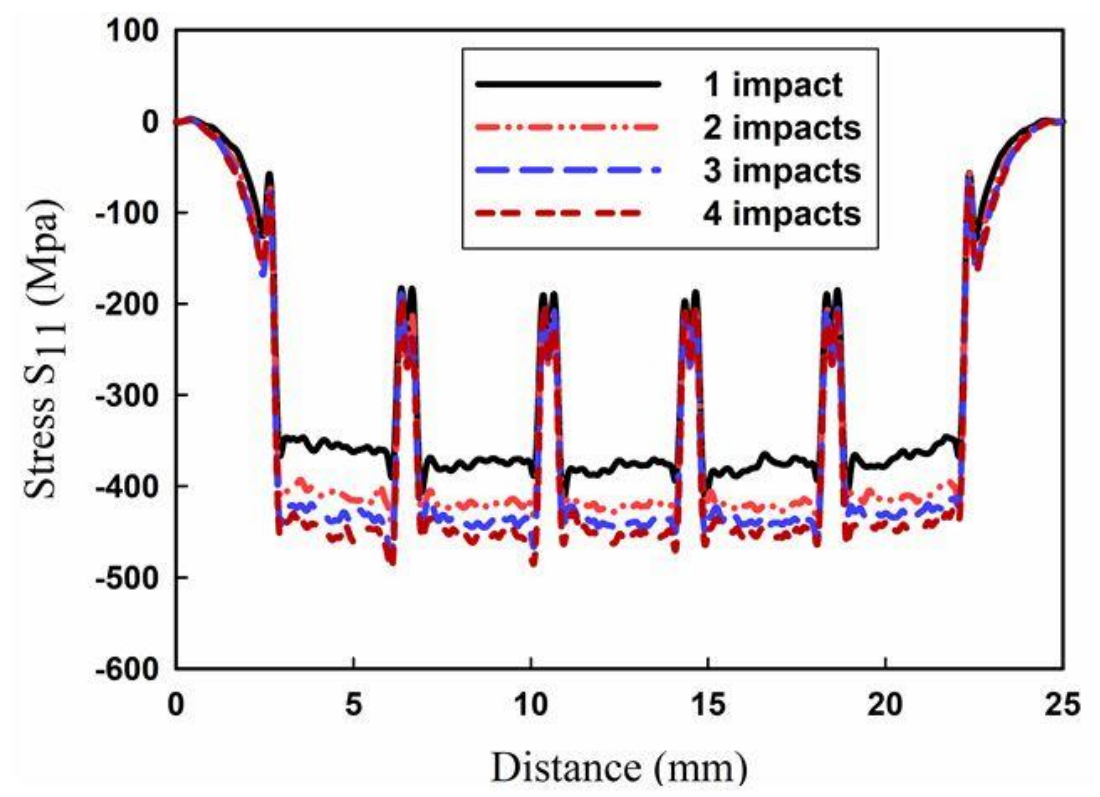

Fig. 9. Effects of multiple laser impacts on surface residual stress

\section{4- Experimental investigation of LSP effects on fatigue crack growth}

\section{1- Material selection and specimen preparation}

316L stainless steel, which is widely used in chemical, petrochemical and power industries, is selected for experimental testing in this work. The mechanical properties of the supplied material are determined experimentally by performing a tensile test at room temperature according to ASTM E8/E8M standard [48]. The yield strength $\sigma_{y}$ and Ultimate Tensile Strength (UTS) are determined as $320 \mathrm{MPa}$ and $594 \mathrm{MPa}$, respectively. The elastic modulus $E$ and strain at failure of $187 \mathrm{GPa}$ and $57 \%$ were obtained from the tensile test. As shown in Figure 10 compact tension, C(T), specimens with the width of $W=40 \mathrm{~mm}$ and thickness of $\mathrm{B}=6 \mathrm{~mm}$ were extracted from the supplied material to perform fatigue crack growth (FCG) tests in this study following ASTM E647 standard test method. $\mathrm{C}(\mathrm{T})$ specimens were initially pre-fatigued cracked at room temperature in air by approximately 3 $\mathrm{mm}$ from the initial $\mathrm{V}$-notch tip. The maximum load of $7 \mathrm{kN}$, the load ratio of $R=0.1$, the frequency of $f=4 \mathrm{~Hz}$ and sinusoidal waveforms were used to pre-fatigue crack the test specimens. The initial crack length, after pre-cracking, of around $13 \mathrm{~mm}$ was obtained in all test specimens prior to the main FCG testing phase. An example of a FCG test specimen after pre-cracking is shown in Figure 11. 

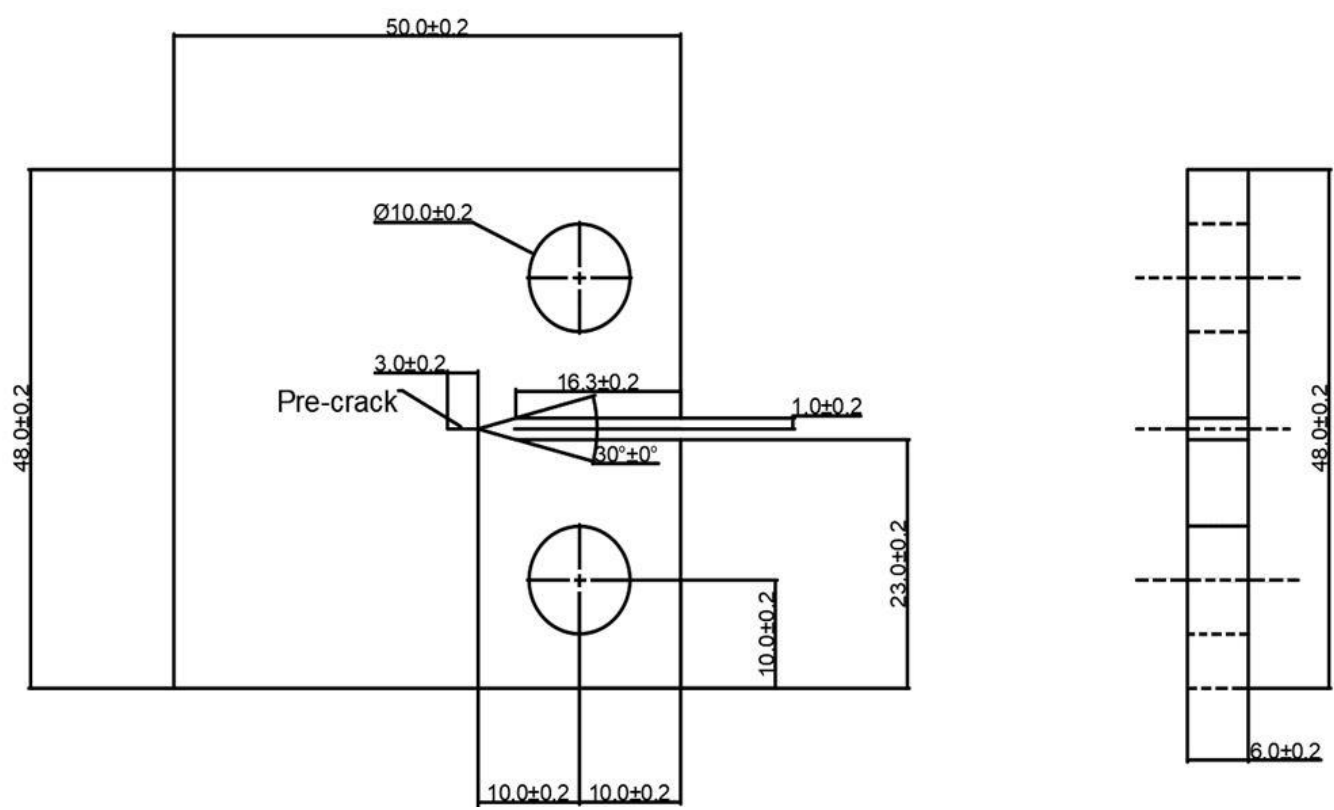

Fig. 10. C(T) specimen dimensions used in the FCG tests, All lengths are specified in mm.

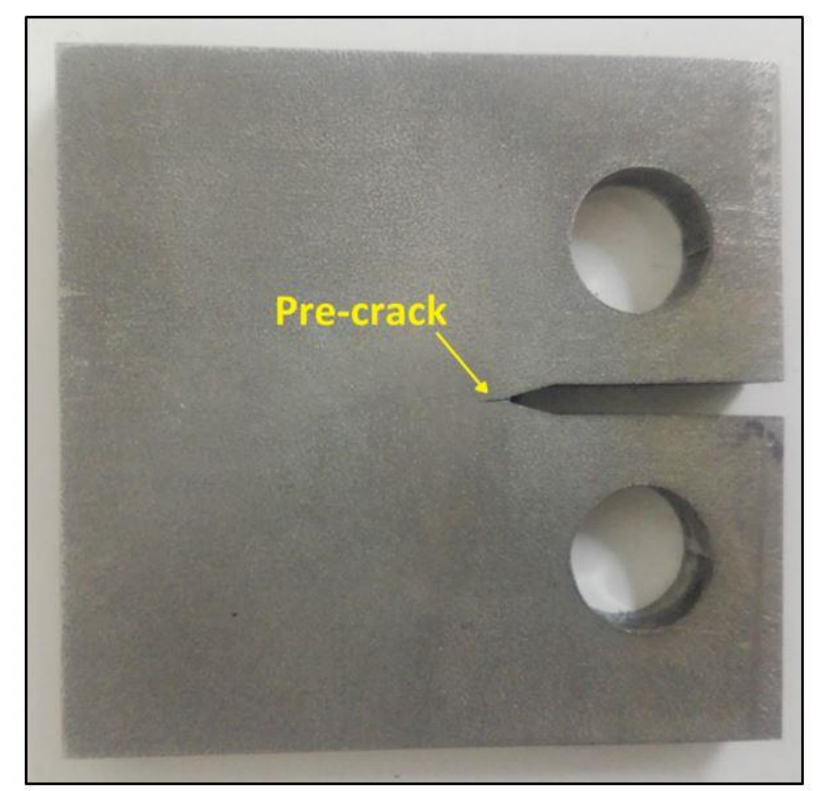

Fig. 11. An example of a C(T) sample after pre-cracking

\section{2- Applying LSP on C(T) specimens}

A Q-switched Nd:Yag laser was used to carry out laser shock peening on $\mathrm{C}(\mathrm{T})$ specimens. The laser repetition rate, laser energy, spot diameter, FWHM and the wavelength were $10 \mathrm{~Hz}, 1.6 \mathrm{~J}, 4 \mathrm{~mm}, 5 \mathrm{~ns}$ and $1064 \mathrm{~nm}$ respectively. Laser shock peening without coating was applied and a thickness of $1 \sim 2$ $\mathrm{mm}$ water jet was used as a transparent overlay. One side of the samples was treated by laser shock peening and the overlapping rate in both the parallel and perpendicular direction was $0 \%$ between the adjacent pulses. Three samples were used for the fatigue crack growth experiments in total, one of 
which was remained untreated for comparison purposes while the other two were LSP treated by applying one and two peening impacts (see Figure 2).

\section{3- Fatigue crack growth testing on LSP specimens}

FCG tests were performed at room temperature in the air using a $250 \mathrm{kN}$ servo hydraulic machine. The maximum applied load of $5 \mathrm{kN}$, the load ratio of $R=0.1$, the test frequency of $f=5 \mathrm{~Hz}$ with a sinusoidal waveform were applied in all three FCG tests. The crack growth monitoring in FCG experiments was conducted using a Dino-Lite Digital Microscope which was connected to a laptop. The FCG test set-up and crack growth monitoring tools are shown in Figure 12.

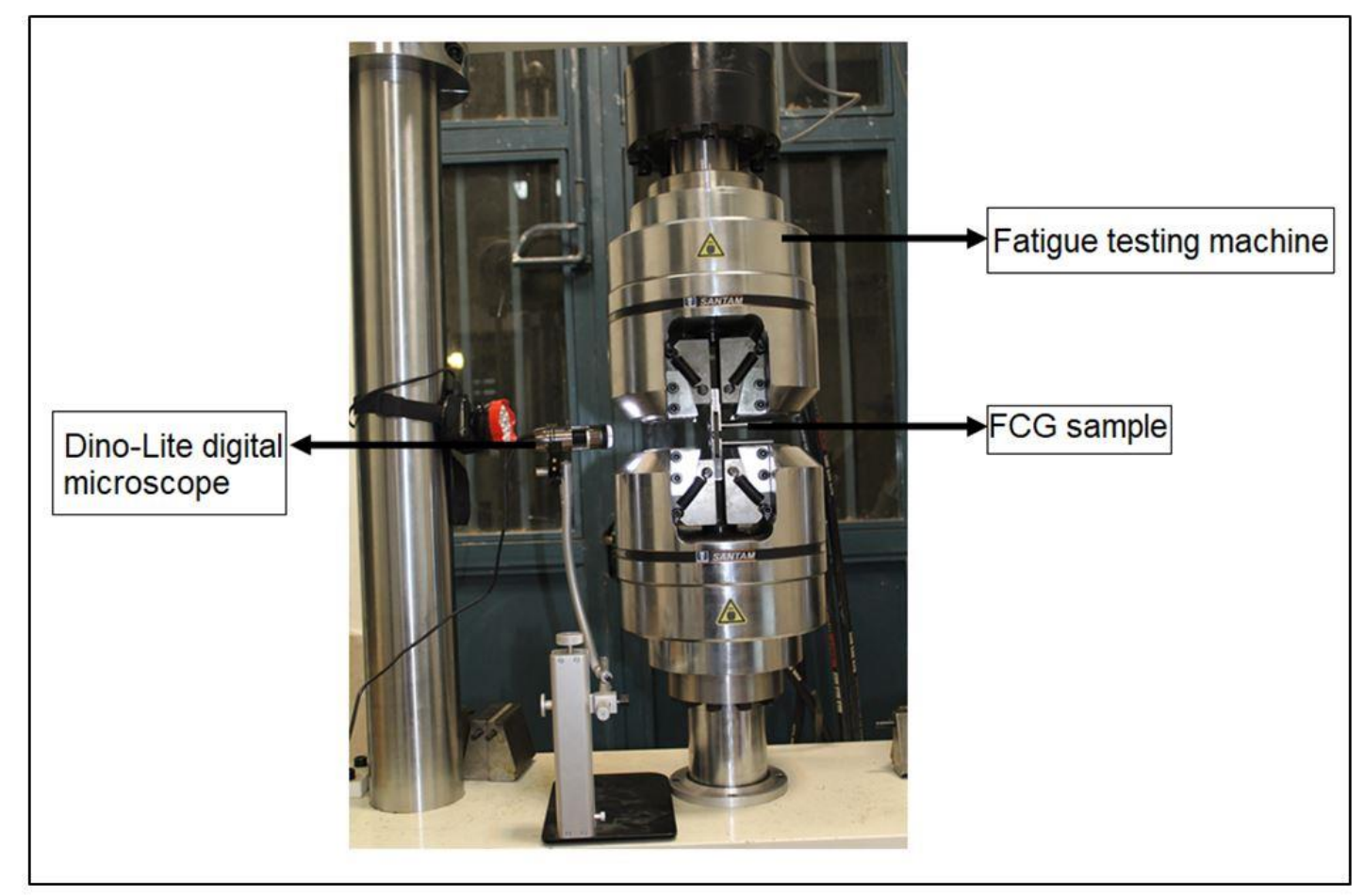

Fig. 12. Fatigue crack growth test set-up

\section{5- Experimental Results from C(T) Specimens with Multiple LSP Impacts}

\section{1- Comparison of fatigue crack growth trends}

The crack length, $a$, versus number of cycles , $N$, results from 3 FCG tests on $\mathrm{C}(\mathrm{T})$ specimens with 0 , 1 and 2 peening impacts are shown in Figure 13. As seen in this figure the crack in untreated sample grew up to $29.5 \mathrm{~mm}$ and after 84380 cycles the sample was broken. In the $\mathrm{C}(\mathrm{T})$ specimen with 1 peening impact, the final fatigue crack length reached $30 \mathrm{~mm}$ and the fatigue life increased has been found to increase to 104130 cycles, compared to the untreated specimen. In the C(T) specimen with 2 peening impacts, the final fatigue crack length increased to $32 \mathrm{~mm}$ and the final fatigue life increased further to 170500 cycles, which is greater than the untreated specimens and the one with 1 
peening impact. An important observation which is made by comparison the results from these three tests is the retardation of fatigue crack growth at the initial stages as a result of LSP. In the untreated sample, 24000 cycles were needed for the first 0.5 crack growth while this cycle number increased to 35141 and 47680 cycles in the C(T) specimens with 1 and 2 peening impacts, respectively. This implies that the fatigue life can be increased by a factor of around two when 2 peening impacts was applied on the $\mathrm{C}(\mathrm{T})$ specimen. Also seen in this figure is that after 84380 cycles the untreated sample reached its critical crack length and failed while the crack had grown to only $6 \mathrm{~mm}$ and $3.5 \mathrm{~mm}$ in the other two samples with 1 and 2 peening impacts applied on them, respectively. This means that by increasing the number of peening impacts larger and deeper compressive residual stress field are induced in the specimens which result in crack growth retardation at different stages of the test.

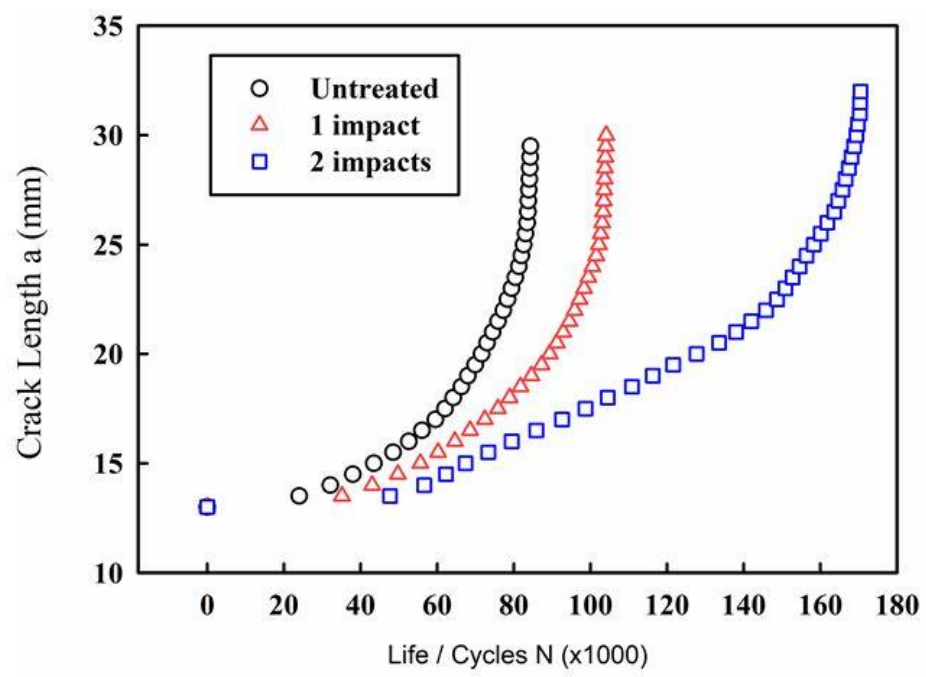

Fig. 13. Crack length versus fatigue life for $316 L$ stainless steel C(T) samples subjected to multiple peening impacts

The fatigue life of all three $\mathrm{C}(\mathrm{T})$ specimens subjected to various peening impacts is summarised in Figure 14. It is evident from this figure that laser peening increases the fatigue life of samples. The experimental results have shown that the fatigue life increases by $23.4 \%$ after the first peening impact. Moreover, it can be seen in Figure 14 that after the second peening impact, the fatigue life increases by around $63.7 \%$ compared to the sample with only one peening impact and by $102 \%$ compared to the untreated sample. This suggests that that repeating the LSP pattern by at least twice can effectively double the fatigue life of the component. 


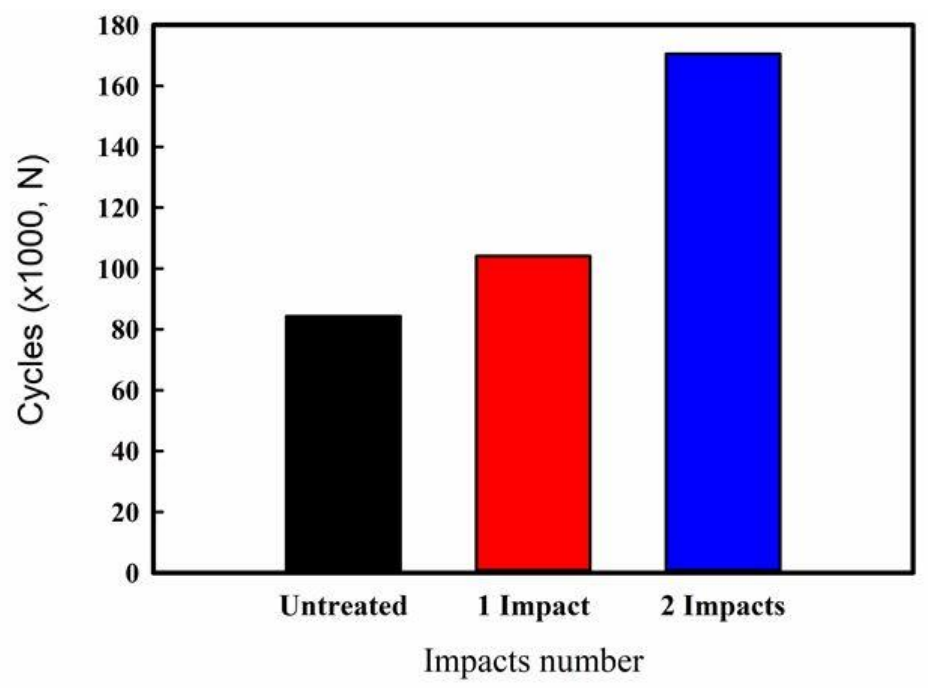

Fig. 14. Comparison of fatigue life in $C(T)$ samples

\section{2- Comparison of the fatigue crack growth rates}

Assuming that the crack growth behaviour in the examined C(T) samples is stable, the Paris formula is adopted to correlate the fatigue crack growth rate with the stress intensity factor range [49]:

$$
\frac{d a}{d N}=C(\Delta K)^{m}
$$

where $a$ is the crack length, $N$ is cycle number, $C$ and $m$ are Paris-law constants, $d a / d N$ is the fatigue crack growth rate and $\Delta K$ is the stress intensity factor range. Stress intensity factor range under mode I fracture mechanics loading condition can be determined using the following equation [50] :

$$
\begin{gathered}
\Delta K=\frac{P_{\max }-P_{\min }}{B \sqrt{W}} \frac{2+\left(\frac{a}{W}\right)}{\left[1-\left(\frac{a}{W}\right)\right]^{3 / 2}}\left[0.886+4.64\left(\frac{a}{W}\right)-13.32\left(\frac{a}{W}\right)^{2}\right. \\
\left.+14.72\left(\frac{a}{W}\right)^{3}-5.60\left(\frac{a}{W}\right)^{4}\right]
\end{gathered}
$$

where $P_{\max }$ and $P_{\min }$ are the maximum and minimum applied loads, $B$ and $W$ are the thickness and width of the sample, and $a$ is the crack length. For determination of fatigue crack growth rate, secant technique [50] is used in which the slope of straight line between two adjacent points on the crack length versus fatigue life is used to calculate $\frac{d a}{d N}$. The fatigue crack growth rate data are plotted against the stress intensity factor range $\Delta K$ in Figure 15. The results show that after applying the first peening impact, there is a slight decline in the slope of FCG trend but after the second peening impact, there is a more pronounced decrease in the slope of the FCG trend which means that the fatigue crack growth rate reduces significantly by repeating LSP pattern. 


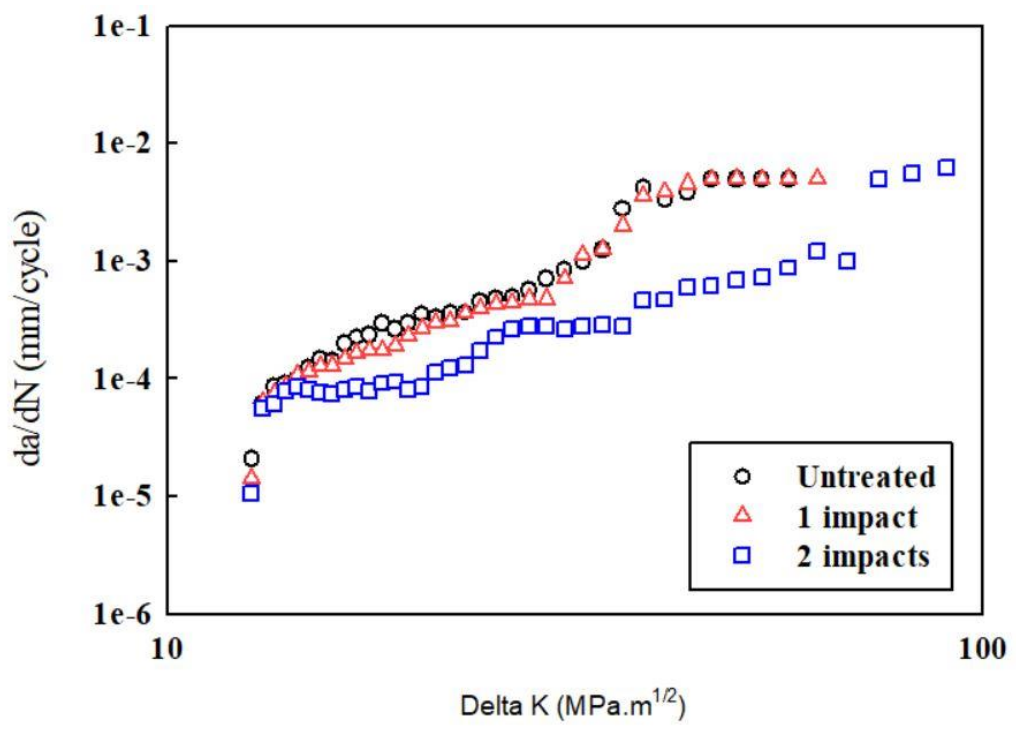

Fig. 15. Fatigue crack growth rate versus stress intensity factor range for $316 \mathrm{~L}$ stainloss stool CT samnlos suhioctod to multinlo imnacts

A line of best fit has been made to the data points presented in Figure 15 to determine the $C$ and $m$ constants for each of the samples examined in this study. The Paris-law constants for each material data set are summarised in table 2. Comparison of the Paris-law constants in untreated sample with the LSP specimens confirms that for a given value of $\Delta K$ the fatigue crack gowth rate significantly reduces by applying 2 peening impacts on the specimens.

\section{Table 2}

$C$ and $m$ constants in Paris-law equation

\begin{tabular}{cccc}
\hline Paris coefficients & untreated & 1 Impact & 2 Impacts \\
\hline$C$ & $2 \times 10^{-11}$ & $1 \times 10^{-11}$ & $1 \times 10^{-10}$ \\
\hline$m$ & 3.186 & 3.240 & 2.298 \\
\hline
\end{tabular}

\section{3- Fracture surface examination}

All three $\mathrm{C}(\mathrm{T})$ specimens were broken open subsequent to the test completion and the fracture surfaces were examined the results of which are presented in Figure 16. The images shown in this figure were captured using a Digital Dino-Lite microscope at $\times 45$ magnification. The fractography analysis reveals that fatigue striations can be clearly seen in all three samples. These lines represent the growth of the crack per cycle. It is obvious that the distance between lines increases slowly which indicates that as the crack propagates, the crack growth rate increases until the crack reaches an 
unstable condition and fracture finally taken place in the test specimen. Fatigue striation spacing (FSS) can be used as an approximation tool for fatigue crack growth rates [27]. As seen in Figure 16, the FSS decreases by applying LSP on the $\mathrm{C}(\mathrm{T})$ specimens due to a deep compressive residual stress field induced by LSP and this reduction is more clear after 2 peening impacts. Another important observation is that the fatigue striation lines in peened specimens (Figure 16 (b) and (c)) have not grown symmetrically unlike the untreated sample (Figure 16 (a)). The crack growth is retarded in one side which is treated by laser peening. This is due to the fact that the compressive residual stress fields induced by laser peening at one side of the specimen reduced the stress intensity factor in the presence of compressive residual stresses, thus the crack growth was retarded at this side.

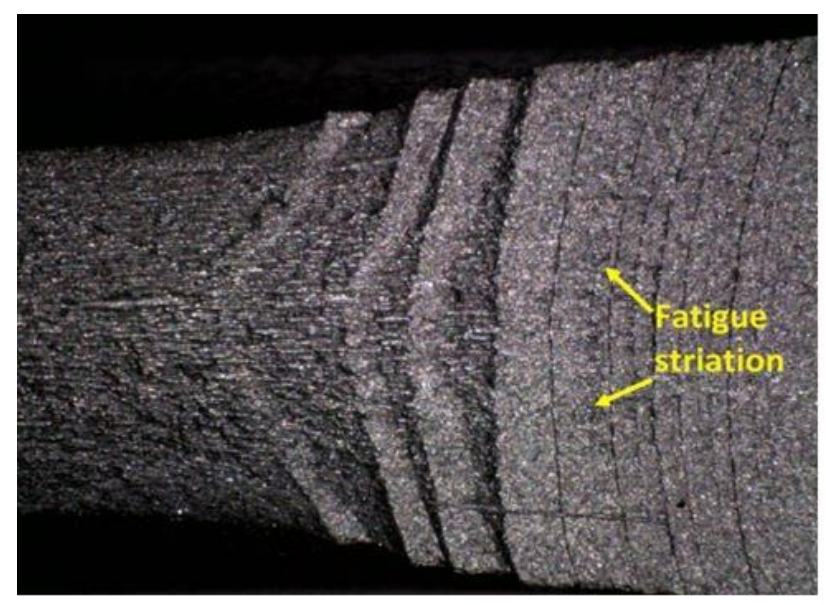

a)

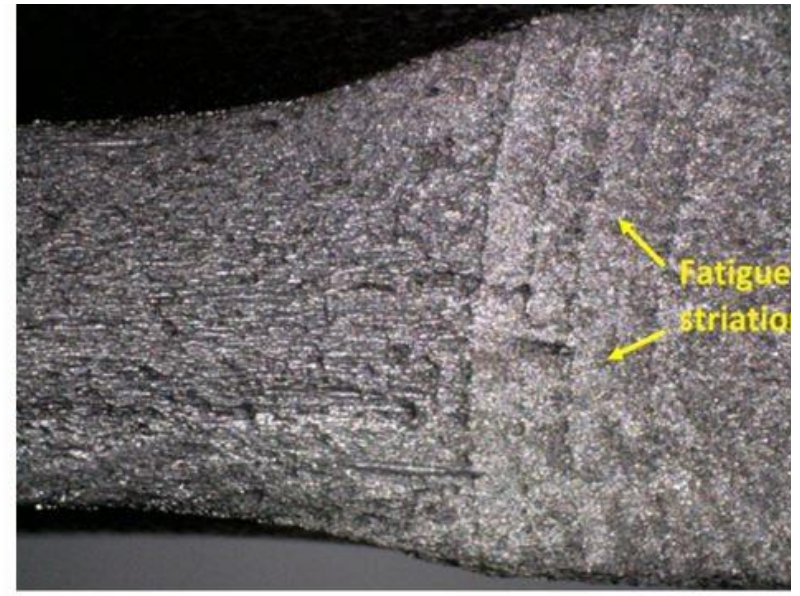

b)

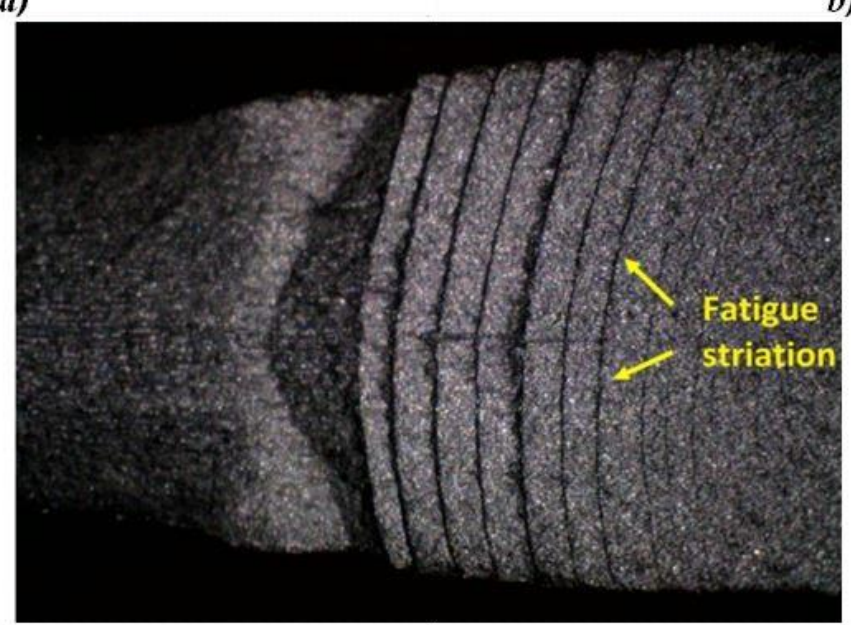

c)

Fig. 16. Fracture surface of $316 \mathrm{~L}$ stainless steel C(T) samples subjected to multiple impacts (a) untreated (b) 1 peening impact (c) 2 peening impacts

\section{6- Conclusions}

Effects of repeating laser shock peening pattern on residual stress profiles was investigated numerically and experimentally in this study. FEM results have shown that increasing the number of peening impact times results in enhancing the magnitude and depth of compressive residual stress. By repeating the laser peening pattern from one, to two, three and four times the peak compressive 
in-depth residual stress rised from 369 to 420, 443 and $452 \mathrm{MPa}$, respectively and the residual stress depth increased from 0.652 to $0.814,0.93$ and $1.005 \mathrm{~mm}$, respectively. Also the magnitude of average surface residual stress in the impact region increased from -291 to $-326,-343$ and $-356 \mathrm{MPa}$ after applying 2, 3 and 4 peening impacts, respectively. According to the FEM results the incremental enhancement of in-depth and surface residual stress from 1 peening impact to two impacts is greater than the incremental changes in subsequent peening impacts (i.e. from 2 to 3 and from 3 to 4 peening impacts). The effects of multiple peening impacts on fatigue crack growth behaviour of $316 \mathrm{~L}$ stainless steel was experimentally examined. The results have shown that the fatigue crack growth life is almost doubled when 2 parents on LSP are applied on the test specimen, compared to the untreated sample.

\section{References}

1. Stephens, R.I., et al., Metal fatigue in engineering. 2000: John Wiley \& Sons.

2. Ge, M.-Z. and J.-Y. Xiang, Effect of laser shock peening on microstructure and fatigue crack growth rate of AZ31B magnesium alloy. Journal of Alloys and Compounds, 2016. 680: p. 544-552.

3. Huang, S., et al., Effects of laser peening with different coverage areas on fatigue crack growth properties of 6061-T6 aluminum alloy. International Journal of Fatigue, 2013. 47: p. 292-299.

4. Zhang, X., et al., Investigation on effect of laser shock processing on fatigue crack initiation and its growth in aluminum alloy plate. Materials \& Design (1980-2015), 2015. 65: p. 425-431.

5. Al-Obaid, Y., Shot peening mechanics: experimental and theoretical analysis. Mechanics of Materials, 1995. 19(2-3): p. 251-260.

6. Srivastava, M., et al., Potential of using water jet peening as a surface treatment process for welded joints. Procedia Engineering, 2016. 149: p. 472-480.

7. Kudryavtsev, Y., et al. Effect of Ultrasonic Peening on microhardness and residual stress in materials and welded elements. in SEM International Congress and Exposition on Experimental and Applied Mechanics. Costa Mesa, California, USA, June 7-10, 2004.(on CD). 2004.

8. Masse, J.-E. and G. Barreau, Laser generation of stress waves in metal. Surface and Coatings Technology, 1995. 70(2-3): p. 231-234.

9. $\quad$ Ding, K. and L. Ye, Laser shock peening: performance and process simulation. 2006: Woodhead Publishing.

10. Montross, C., V. Florea, and M. Swain, The influence of coatings on subsurface mechanical properties of laser peened 2011-T3 aluminum. Journal of Materials Science, 2001. 36(7): p. 1801-1807.

11. Sano, Y., et al., Residual stress improvement in metal surface by underwater laser irradiation. Nuclear Instruments and Methods in Physics Research Section B: Beam Interactions with Materials and Atoms, 1997. 121(1-4): p. 432-436.

12. Peyre, P., et al., Laser shock processing of aluminium alloys. Application to high cycle fatigue behaviour. Materials Science and Engineering: A, 1996. 210(1-2): p. 102-113. 
13. Yang, J.-M., et al., Laser shock peening on fatigue behavior of 2024-T3 Al alloy with fastener holes and stopholes. Materials Science and Engineering: A, 2001. 298(1-2): p. 296-299.

14. Sticchi, M., et al., A parametric study of laser spot size and coverage on the laser shock peening induced residual stress in thin aluminium samples. The Journal of Engineering, 2015. 2015(13): p. $97-$ 105.

15. Huang, S., et al., Effects of laser energy on fatigue crack growth properties of 6061-T6 aluminum alloy subjected to multiple laser peening. Engineering Fracture Mechanics, 2013. 99: p. 87-100.

16. Kim, J.H., Y.J. Kim, and J.S. Kim, Effects of simulation parameters on residual stresses for laser shock peening finite element analysis. Journal of Mechanical Science and Technology, 2013. 27(7): p. 2025-2034.

17. Vasu, A. and R.V. Grandhi, Effects of curved geometry on residual stress in laser peening. Surface and Coatings Technology, 2013. 218: p. 71-79.

18. Cao, Y., Y.C. Shin, and B. Wu, Parametric study on single shot and overlapping laser shock peening on various metals via modeling and experiments. Journal of Manufacturing Science and Engineering, 2010. 132(6): p. 061010.

19. $\mathrm{Hu}, \mathrm{Y}$. and Z. Yao, Overlapping rate effect on laser shock processing of 1045 steel by small spots with Nd: YAG pulsed laser. Surface and Coatings Technology, 2008. 202(8): p. 1517-1525.

20. Ding, K. and L. Ye, Simulation of multiple laser shock peening of a 35CD4 steel alloy. Journal of Materials Processing Technology, 2006. 178(1-3): p. 162-169.

21. Peyre, P., I. Chaieb, and C. Braham, FEM calculation of residual stresses induced by laser shock processing in stainless steels. Modelling and simulation in materials science and engineering, 2007. 15(3): p. 205.

22. Ding, K., Three-dimensional dynamic finite element analysis of multiple laser shock peening processes. Surface Engineering, 2003. 19(5): p. 351-358.

23. Wei, X. and X. Ling, Numerical modeling of residual stress induced by laser shock processing. Applied Surface Science, 2014. 301: p. 557-563.

24. $\mathrm{Hu}, \mathrm{Y} ., \mathrm{Z}$. Yao, and J. Hu, 3-D FEM simulation of laser shock processing. Surface and Coatings Technology, 2006. 201(3-4): p. 1426-1435.

25. Lu, J., et al., Grain refinement mechanism of multiple laser shock processing impacts on ANSI 304 stainless steel. Acta Materialia, 2010. 58(16): p. 5354-5362.

26. Zhang, X., et al., Improvement of fatigue life of Ti-6Al-4V alloy by laser shock peening. Materials Science and Engineering: A, 2010. 527(15): p. 3411-3415.

27. Zhou, J., et al., Effect of repeated impacts on mechanical properties and fatigue fracture morphologies of 6061-T6 aluminum subject to laser peening. Materials Science and Engineering: A, 2012. 539: p. 360-368.

28. Liucheng, Z., et al., Effect of multiple laser shock processing on microstructure and mechanical properties of Ti-5Al-4Mo-4Cr-2Sn-2Zr titanium alloy. Rare metal materials and engineering, 2014. 43(5): p. 1067-1072. 
29. Shen, X., et al., Improvement in mechanical properties of titanium alloy (Ti-6Al-7Nb) subject to multiple laser shock peening. Surface and Coatings Technology, 2017. 327: p. 101-109.

30. Umapathi, A. and S. Swaroop, Deformation of single and multiple laser peened TC6 titanium alloy. Optics \& Laser Technology, 2018. 100: p. 309-316.

31. Wang, H., et al., Investigation of multiple laser shock peening on the mechanical property and corrosion resistance of shipbuilding 5083 Al alloy under a simulated seawater environment. Applied optics, 2018. 57(22): p. 6300-6308.

32. Yang, Y., et al., Effects of laser shock peening on microstructures and properties of 2195 Al-Li alloy. Journal of Alloys and Compounds, 2019. 781: p. 330-336.

33. $\mathrm{Li}$, J., et al., Influence of multiple laser peening on vibration fatigue properties of TC6 titanium alloy. Optics \& Laser Technology, 2019. 118: p. 183-191.

34. Chen, H., et al., Effects of Multiple Laser Peening impacts on Mechanical Properties and Microstructure Evolution of 40CrNiMo Steel. Journal of Materials Engineering and Performance, 2019. 28(5): p. 2522-2529.

35. Johnson, G.R., A constitutive model and data for materials subjected to large strains, high strain rates, and high temperatures. Proc. 7th Inf. Sympo. Ballistics, 1983: p. 541-547.

36. Correa, C., et al., Effect of advancing direction on fatigue life of $316 \mathrm{~L}$ stainless steel specimens treated by double-sided laser shock peening. International Journal of Fatigue, 2015. 79: p. 1-9.

37. Hfaiedh, N., et al., Finite element analysis of laser shock peening of 2050-T8 aluminum alloy. International Journal of Fatigue, 2015. 70: p. 480-489.

38. Braisted, W. and R. Brockman, Finite element simulation of laser shock peening. International Journal of Fatigue, 1999. 21(7): p. 719-724.

39. Peyre, P., et al., FEM simulation of residual stresses induced by laser peening. The European Physical Journal-Applied Physics, 2003. 23(2): p. 83-88.

40. Ballard, P., et al., Residual stresses induced by laser-shocks. Le Journal de Physique IV, 1991. 1(C3): p. C3-487-C3-494.

41. Berthe, L., et al., Shock waves from a water-confined laser-generated plasma. Journal of Applied Physics, 1997. 82(6): p. 2826-2832.

42. Achintha, M. and D. Nowell, Eigenstrain modelling of residual stresses generated by laser shock peening. Journal of Materials Processing Technology, 2011. 211(6): p. 1091-1101.

43. Singh, G., R.V. Grandhi, and D.S. Stargel, Modeling and parameter design of a laser shock peening process. International Journal for Computational Methods in Engineering Science and Mechanics, 2011. 12(5): p. 233-253.

44. Li, X., et al., Simulation and Experimental Study on Residual Stress Distribution in Titanium Alloy Treated by Laser Shock Peening with Flat-Top and Gaussian Laser Beams. Materials, 2019. 12(8): p. 1343.

45. Amarchinta, H., et al., Material model validation for laser shock peening process simulation. Modelling and simulation in materials science and engineering, 2008. 17(1): p. 015010. 
46. Singh, G., Effective Simulation and Optimization of a Laser Peening Process. 2009.

47. Zheng, C., et al., Numerical simulation and experimentation of micro scale laser bulge forming. International Journal of Machine Tools and Manufacture, 2010. 50(12): p. 1048-1056.

48. Testing, A.S.f. and M.C.E.-o.M. Testing, Standard test Method for tension testing of metallic materials. 2015: ASTM International.

49. Paris, P. and F. Erdogan, A critical analysis of crack propagation laws. Journal of basic engineering, 1963. 85(4): p. 528-533.

50. Standard, A., E647, Standard test method for measurement of fatigue crack growth rates. Annual Book of ASTM Standards, Section Three: Metals Test Methods and Analytical Procedures, 2002. 3: p. 628670. 